\title{
Radiographic Evaluation of Infraorbital Canal Protrusion into Maxillary Sinus Using Cone-Beam Computed Tomography
}

\author{
Fahrettin Kalabalık', Tunahan Aktaş ${ }^{1}$, Ender Akan², Emre Aytuğar $^{1}$ \\ ${ }^{1}$ Department of Oral and Maxillofacial Radiology, Faculty of Dentistry, Izmir Katip Celebi University, Izmir, Turkey. \\ ${ }^{2}$ Department of Prosthodontics, Faculty of Dentistry, İzmir Katip Çelebi University, Izmir, Turkey.
}

\author{
Corresponding Author: \\ Fahrettin Kalabalık \\ Aydinlikevler Mahallesi, Cemil Meric Bulvari, 6780 Sokak. No:48, 35640 Cigli/Izmir \\ Turkey
}

Phone: 902323254040

Fax: +902323252535

E-mail: kalabalikfahrettin@hotmail.com

\begin{abstract}
Objectives: The aim of this retrospective study was to evaluate the relation of the infraorbital canal course with the maxillary sinus using cone-beam computed tomography.

Material and Methods: A total of 1000 infraorbital canals (IOC) were examined from 500 cone-beam computed tomography scans. IOCs were classified into three types based on the degree of protrusion into the sinus. The presence of Haller cells and mucosal thickening in the sinus were evaluated. The length of bony septum from the canal to the sinus wall (D1), the distance at which protrusion begins posterior to the inferior orbital rim (D2), the vertical distance from the canal to the sinus roof (D3), and the vertical distance from the canal to the sinus floor (D4) were measured.

Results: The prevalence of IOC protrusion into the sinus was $8.8 \%$. There was a significant difference in the prevalence of Haller cells between IOC types $(\mathrm{P}<0.01)$. However, no significant correlation was found between IOC types and the presence of mucosal thickening $(\mathrm{P}>0.05)$. There was no significant difference in the mean D1, D2, and D3 between the genders $(\mathrm{P}>0.05)$. The mean $\mathrm{D} 4$ was significantly higher in males than in females $(\mathrm{P}<0.05)$.

Conclusions: The protrusion of infraorbital canals into the sinus is a common variation that must be considered to prevent accidental injury. Our findings suggest that the risk of injury to the descending canals is very low during routine dentoalveolar procedures because the protruded canal is not close to the sinus floor.
\end{abstract}

Keywords: cone-beam computed tomography; maxillary nerve; maxillary sinus; trigeminal nerve.

\footnotetext{
Accepted for publication: 28 December 2020

To cite this article:

Kalabalık F, Aktaş T, Akan E, Aytuğar E.

Radiographic Evaluation of Infraorbital Canal Protrusion into Maxillary Sinus Using Cone-Beam Computed Tomography

J Oral Maxillofac Res 2020;11(4):e5

URL: http://www.ejomr.org/JOMR/archives/2020/4/e5/v11n4e5.pdf

doi: $10.5037 /$ jomr.2020.11405
} 


\section{INTRODUCTION}

The infraorbital nerve (ION) is the terminal and largest branch of the maxillary nerve which originates as the second division of the trigeminal nerve. The maxillary nerve exits the middle cranial fossa through the foramen rotundum and enters the pterygopalatine fossa. After giving off nasal and palatine branches it enters the orbit via the inferior orbital fissure and it terminates as the ION. The ION then enters the infraorbital canal (IOC) through the infraorbital groove and exits normally from the infraorbital foramen of the maxillary bone $[1,2]$. It is responsible for the sensory innervation of the skin of the lower eyelid, conjunctiva, upper lip, and lateral surface of the nose [ $\underline{3}]$.

Damage to the ION and the infraorbital artery is rare in routine endoscopic surgery of the maxillary sinus since the ION and the infraorbital artery are protected by the IOC. However, the protrusion of the ION renders them prone to accidental injury during medical and dental procedures such as CaldwellLuc surgery, rhinoplasty, endoscopic sinus surgery, maxillary resections, and tumor removal from the maxilla and maxillary sinus $[\underline{1}, \underline{4}]$.

Preoperative radiological assessment of the IOC is essential to prevent accidental injuries during surgical procedures involving the maxillary sinus [5] . Computerized tomography (CT) is widely accepted to be the best imaging method in the radiologic investigation of the paranasal sinuses and other neighboring structures [] $]$. Cone-beam computed tomography $(\mathrm{CBCT})$ is a relatively new technology in the field of oral and maxillofacial radiology. CBCT is accepted as a fast and efficient alternative to CT in paranasal sinus imaging due to higher spatial resolution, lower patient dose, and lower cost $[7, \underline{8}]$.

The course of IOC is widely regarded as being important when considering surgical procedures involving the maxillary sinus, but only a few studies have investigated the relationship of IOC with the sinus. The aim of this retrospective study was to evaluate the relation of the infraorbital canals course with the maxillary sinus and to estimate the prevalence of infraorbital canals protrusion into the sinus using cone-beam computed tomography.

\section{MATERIAL AND METHODS}

This retrospective study was approved by the Izmir Katip Celebi University Non-Interventional Clinical Studies Institutional Review Board (No. 2020/990).
All of the patients in our department's CBCT archive have provided written consent regarding the use of their radiologic data for scientific research. The data of 500 randomly selected patients who had undergone CBCT imaging between October, 2012 and May, 2020 at the Izmir Katip Çelebi University, Faculty of Dentistry were evaluated. The CBCT scans had been prescribed for various reasons such as implant planning, third molar extraction, orthodontic treatment, etc. All CBCT scans were obtained using NewTom ${ }^{\mathrm{TM}}$ 5G (QR Verona, s.r.l.; Verona, Italy). Voxel size and slice thickness were $0.2 \mathrm{~mm}$ and $1 \mathrm{~mm}$, respectively. One hundred ten $\mathrm{kVp}, 1-20 \mathrm{~mA}, 15 \times 12 \mathrm{~mm}$ FOV were the imaging parameters. The images were examined using NNT viewer software ver. 9.1 (QR Verona, s.r.l.; Verona, Italy) on a medical monitor Radiforce MX270W (Eizo Co.; Ishikawa, Japan) in a dark room. Images with poor quality due to artefacts, patients with abnormalities in the sinus wall morphology due to trauma or pathological conditions, patients who had undergone sinus surgery or have grafting history, and dental implants in the maxillary premolar-molar region were excluded from the study. Images of 1000 IOCs were reviewed in consensus by two maxillofacial radiologists (FK and EA) with 8 and 11 years of experience in CBCT imaging. Before the evaluation, each image was oriented in such a way that the hard palate was parallel to the floor, while the sagittal plane was perpendicular to the floor. IOCs were classified into three types according to the degree of protrusion of the canal from the maxillary roof into the sinus as described by Ference et al. [1]:

- Type 1 - IOC is totally contained within the maxillary sinus roof.

- Type 2 - IOC is located below the sinus roof but remaining juxtaposed to it.

- Type 3 - IOC descends into the sinus lumen, suspended from the sinus roof within a septa or the lamella of an infraorbital ethmoid cell (Figure 1).

The presence of the Haller cell and mucosal thickening in the maxillary sinus was also inspected on the coronal images. When mucosal thickness exceeded $\geq 3 \mathrm{~mm}$ in the sinus it was considered as mucosal thickening [9].

Four different distances were measured for Type 3 IOC by FK. The maximum length of the bony septum from the canal to the wall of the maxillary sinus (D1) was measured on axial images (Figure 2). On the parasagittal images, the distance from the inferior orbital rim where the infraorbital canal begins to protrude into the maxillary sinus (D2) was measured (Figure 3). On the coronal images, the maximum vertical distances from the canal to the sinus roof (D3) and from the canal to the sinus floor (D4) were measured (Figure 4). 


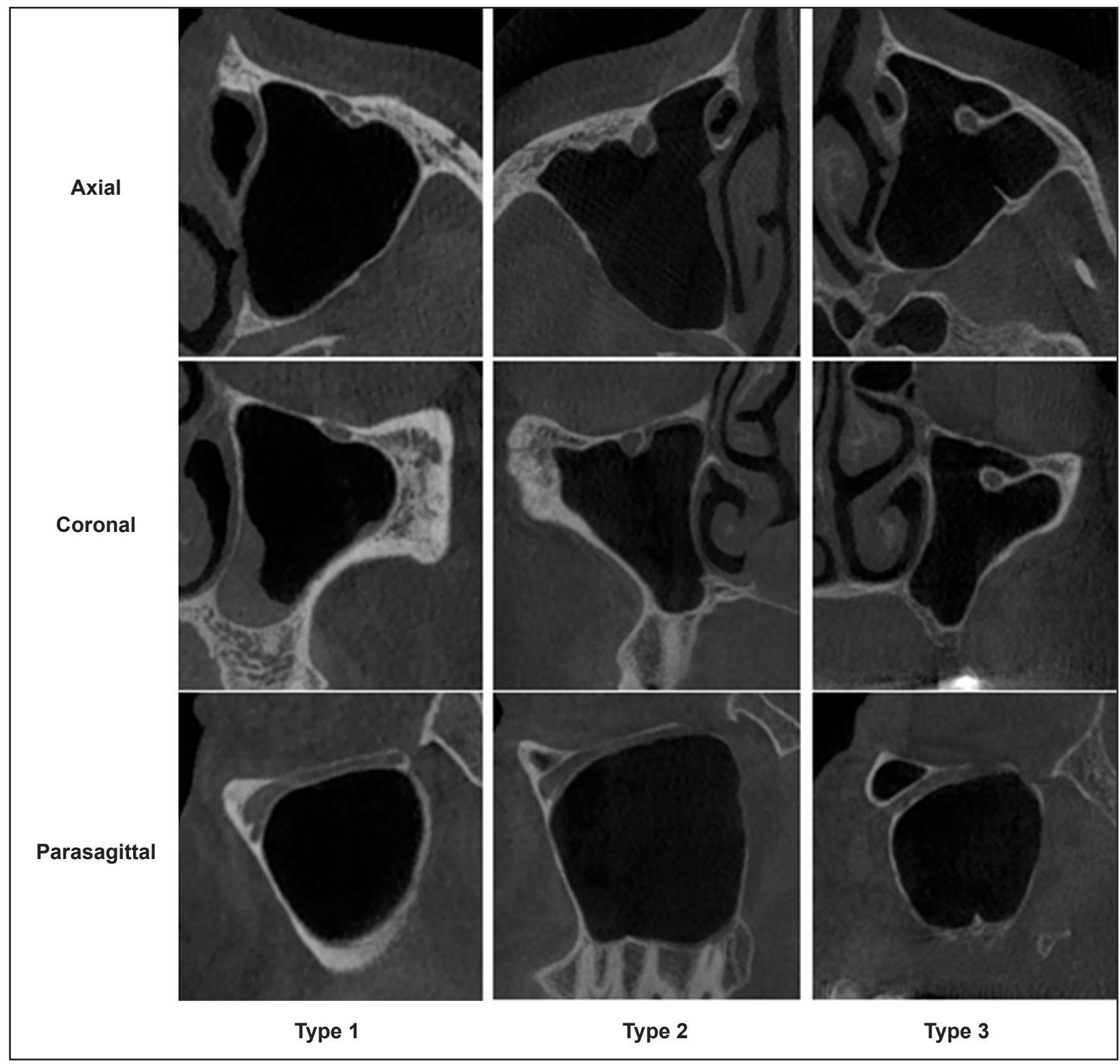

Figure 1. Axial, coronal and parasagittal examples of infraorbital canals types based on the protrusion degree of the canal from the maxillary roof into the sinus.

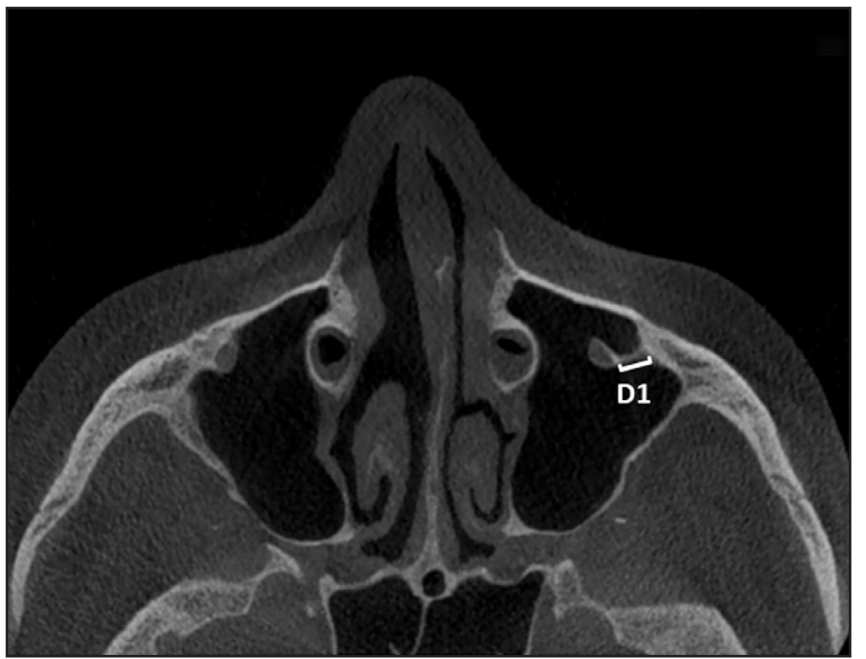

Figure 2. D1 = maximum length of the bony septum from the canal to the wall of the maxillary sinus.

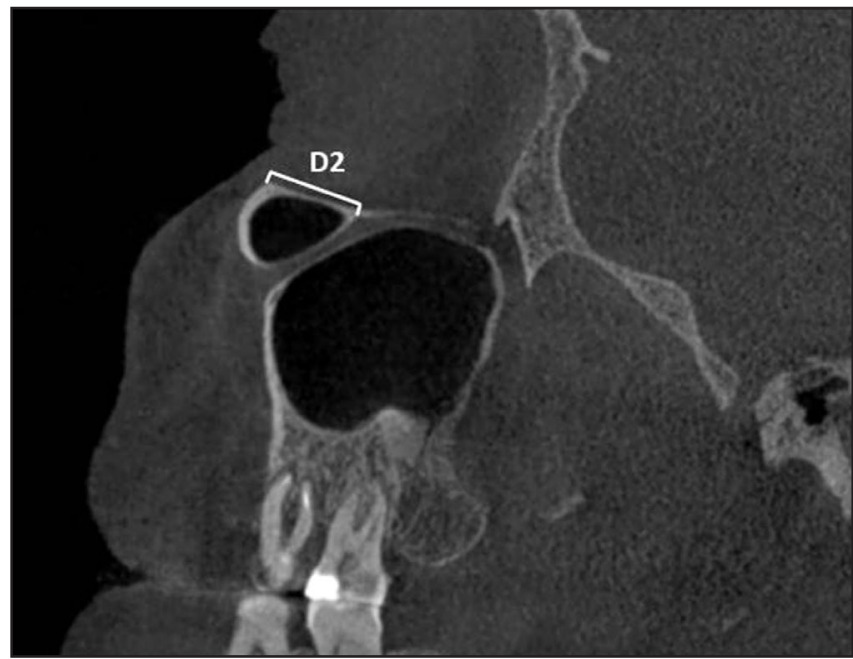

Figure 3. D2 = distance from the inferior orbital rim where the infraorbital canal begins to protrude into the maxillary sinus. 


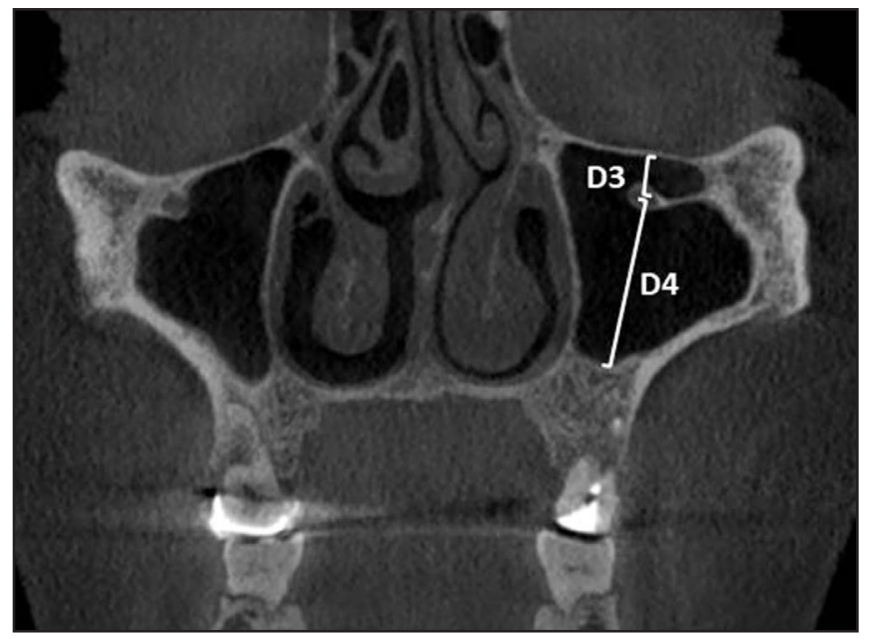

Figure 4. D3 = vertical distance from the canal to the sinus roof. D4 $=$ vertical distance from the canal to the sinus floor.

\section{Statistical analysis}

The statistical analyses were performed using the IBM SPSS Statistics 22.0 (IBM Corp., Armonk, New York, USA) statistical package program. Descriptive analysis was performed by summarizing categorical variables through counts and proportions (\%), and continuous variables by their mean and standard deviation $(\mathrm{M}[\mathrm{SD}])$. The type and frequency of the IOC according to gender, presence of Haller cells, and the presence of mucosal thickening were evaluated by utilizing the Chi-square test. An independent samples t-test was used to compare the gender differences of the mean linear measurements. Differences at the level of $\mathrm{P}<0.05$ were accepted to be statistically significant. For reliability testing, approximately $30 \%$ of Type 3 IOC images were randomly selected for repeated measurements at 3 weeks after the first examination by the same investigator (FK). The intraclass correlation coefficient was used to determine the reliability of the measurements. Moreover, a paired samples t-test was used to assess the systemic error in the differences between the 2 readings.

\section{RESULTS}

Two hundred and fifty-one (50.2\%) of the 500 patients (1,000 sides) whose maxillary sinus CBCT images were evaluated were males and 249 (49.8\%) were females. The ages of the patients ranged between 18 and 87, with a mean age of 45.37 (15.39) years. The coefficient of reliability was above 0.95 for all measurements. The results of the paired samples t-test revealed no significant difference between the two sets of readings, confirming that all the measurements were free of systemic error $(\mathrm{P}>0.05)$.

Five hundred and fifty-two $(55.2 \%)$ of the IOCs were categorized as Type $1,360(36 \%)$ as Type 2, and $88(8.8 \%)$ of the IOCs as Type 3. No significant difference was found in the prevalence of IOC types either when comparing the right and left sides or males and females $(P>0.05)$ (Table 1). The Haller cell was present in $10.7 \%$ of all images, with similar rates on the right and left sides. However, there was a significant difference in the prevalence of Haller cells between IOC types $(\mathrm{P}<0.01)$. The prevalence of Haller cells was found to be significantly higher in Types 2 and 3 than in Type 1. On the other hand, there was no significant difference in the prevalence of Haller cells when comparing Types 2 and 3 (Table 2). Moreover, the prevalence of Type 3 increased from $8.2 \%$ in cases without an ipsilateral Haller cell to $14 \%$ when a Haller cell was present, but the difference was not significant $(\mathrm{P}>0.05)$. The mucosal thickening was present in $27.1 \%$ of all images, with similar rates on the right and left sides. No statistically significant correlation was found between specific IOC types and the presence of mucosal thickening. There was no significant difference in the prevalence of Type 3 between cases with mucosal thickening and cases without mucosal thickening $(\mathrm{P}>0.05)$ (Table 2).

The mean D1, D2, D3, and D4 were found to be $3.75(1.76) \mathrm{mm}$ (range 1.3 to $10.1 \mathrm{~mm}$ ), 9.51 (2.03) $\mathrm{mm}$ (range 5.9 to $14.8 \mathrm{~mm}$ ), $6.76(1.78) \mathrm{mm}$

Table 1. The prevalence of infraorbital canal types according to gender and side

\begin{tabular}{c|c|c|c|c|c|c}
\hline \multirow{2}{*}{$\begin{array}{c}\text { Canal } \\
\text { type }\end{array}$} & Female & Male & \multirow{3}{*}{ P-value } & $\begin{array}{c}\text { Right } \\
\text { side }\end{array}$ & $\begin{array}{c}\text { Left } \\
\text { side }\end{array}$ & \multirow{2}{*}{ P-value } \\
\cline { 2 - 3 } & $\mathbf{N}(\mathbf{\%})$ & $\mathbf{N}(\%)$ & & $\mathbf{N}(\%)$ & $\mathbf{N}(\%)$ & \\
\hline Type 1 & $285(57.2)$ & $267(53.2)$ & & $274(54.8)$ & $278(55.6)$ & \multirow{2}{*}{$0.958^{\text {a }}$} \\
\cline { 1 - 3 } Type 2 & $168(33.7)$ & $192(38.2)$ & \multirow{2}{*}{$0.33^{\mathrm{a}}$} & $181(36.2)$ & $179(35.8)$ & \\
\cline { 1 - 2 } \cline { 5 - 6 } Type 3 & $45(9.1)$ & $43(8.6)$ & & $45(9)$ & $43(8.6)$ & \\
\hline Total & $498(100)$ & $502(100)$ & & $500(100)$ & $500(100)$ & \\
\hline
\end{tabular}

${ }^{a}$ Not significant, Chi-square test (significance level $\mathrm{P}<0.05$ ).

$\mathrm{N}=$ number. 
Table 2. Distribution of the infraorbital canal types according to absence and presence of Haller cells and mucosal thickening

\begin{tabular}{l|c|c|c|c}
\hline & Type 1 & Type 2 & Type 3 & \multirow{2}{*}{ P-value } \\
\cline { 2 - 4 } & N (\%) & N (\%) & N (\%) & \\
\hline Haller cell & $31(5.6)$ & $61(16.9)$ & $15(17)$ & \multirow{2}{*}{$0.000^{\mathrm{a}}$} \\
\hline Present & $521(94.4)$ & $299(83.1)$ & $73(83)$ & \\
\hline Absent & $157(28.4)$ & $93(25.8)$ & $21(23.9)$ & \multirow{2}{|c}{$0.532^{\mathrm{b}}$} \\
\hline Mucosal thickening & \multicolumn{5}{|l}{} \\
\hline Present & $395(71.6)$ & $267(74.2)$ & $67(76.1)$ & \\
\hline Absent &
\end{tabular}

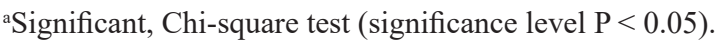

${ }^{b}$ Not significant, Chi-square test (significance level $\mathrm{P}<0.05$ ).

(range 3.3 to $10.7 \mathrm{~mm}$ ), and 25.44 (4.69) $\mathrm{mm}$ (range 14.2 to $36.4 \mathrm{~mm}$ ), respectively. There was no significant difference in the mean D1, D2, and D3 between males and females $(\mathrm{P}>0.05)$. The mean D4 was significantly higher in males than in females $(\mathrm{P}<0.05)$ (Table 3).

\section{DISCUSSION}

Different imaging techniques may be used in order to assess the anatomic variants and pathologies of the paranasal sinuses. The gold standard in evaluation of paranasal sinus anatomy and inflammatory paranasal sinus pathologies is widely accepted to be computed tomography (CT) due to its capability of detailed imaging of both bony and soft tissue structures [10]. Magnetic resonance imaging (MRI) provides an excellent soft tissue contrast resolution, but possesses the limitation of poor spatial resolution and lack of bony details [11]. CBCT is an exciting technology in the field of oral and maxillofacial radiology but is generally accepted as one of the pioneering imaging techniques for paranasal sinus evaluation by dentists, maxillofacial radiologists, and otolaryngologists $[\underline{12}, \underline{13}]$. CBCT image evaluation for the nasal cavity and paranasal sinuses provide many advantages, such as low radiation doses when compared with $\mathrm{CT}$ and low cost when compared with MRI [13]. An isotropic voxel of a very small size in CBCT imaging contributes to a high spatial resolution and imaging quality for bone tissues, but results in poor soft tissue resolution as a consequence [14]. Although CT is considered as the gold standard of imaging techniques for evaluating the sinuses, CBCT is a fast and effective alternative to $\mathrm{CT}$ in identifying sinus disease and as a guide for surgical intervention, with considerable radiation dose reduction over CT [7].
Table 3. Comparisons of the distances $(\mathrm{mm})$ between males and females

\begin{tabular}{c|c|c|c|c}
\hline \multirow{2}{*}{ Distance } & Males & Females & All cases & \multirow{2}{*}{ P-value } \\
\cline { 2 - 4 } & Mean (SD) & Mean (SD) & Mean (SD) & \\
\hline D1 & $3.81(1.51)$ & $3.68(1.98)$ & $3.75(1.76)$ & $0.736^{\mathrm{b}}$ \\
\hline D2 & $9.36(1.85)$ & $9.65(2.2)$ & $9.51(2.03)$ & $0.505^{\mathrm{b}}$ \\
\hline D3 & $6.7(1.69)$ & $6.82(1.87)$ & $6.76(1.78)$ & $0.745^{\mathrm{b}}$ \\
\hline D4 & $26.52(5.24)$ & $24.41(3.88)$ & $25.44(4.69)$ & $0.034^{\mathrm{a}}$ \\
\hline
\end{tabular}

${ }^{a}$ Significant, independent samples t-test (significance level $\mathrm{P}<0.05$ ). ${ }^{b}$ Not significant, independent samples t-test (significance level $\mathrm{P}<0.05)$.

D1 = maximum length of the bony septum from the canal to the wall of the maxillary sinus; D2 = distance from the inferior orbital rim where the infraorbital canal begins to protrude into the maxillary sinus; D3 = maximum vertical distances from the canal to the sinus roof; $\mathrm{D} 4=$ maximum vertical distances from the canal to the sinus floor; $\mathrm{SD}=$ standard deviation .

Functional endoscopic sinus surgery (FESS) is considered as the standard surgical treatment for chronic inflammatory and allergic synonasal disease [5]. FESS technique is based on the theory that the opening of the blocked pathway of osteomeatal drainage complexes reestablishes the normal ventilation of the paranasal sinuses in cases of chronic sinusitis. Despite the advent of FESS, an external approach to the maxillary sinus using the CaldwellLuc operation is still one of the preferred methods in various situations such as chronic rhinosinusitis, paranasal papilloma and foreign body removal [15]. The protrusion of the IOC makes the ION vulnerable to iatrogenic injury during both FESS and CaldwellLuc surgery $[\underline{5}, \underline{16}]$. Preoperative identification of this variant offers a good road map for the surgeons to prevent iatrogenic injuries during surgery [17].

In the present study, 1000 IOCs of 500 patients were evaluated using CBCT images. The prevalence of descended into the maxillary sinus was found to be at $8.8 \%$. This prevalence rate was found to be lower than in the previous studies reported by Ference et al. [1] at $12.5 \%$, by Yenigun et al. [ [6] at $12.3 \%$, by Lantos et al. [2] at $10.8 \%$, Gautam et al. [17] at $11.4 \%$, and Haghnegahdar et al. [4] at $23.2 \%$. In our study, IOCs were also classified into three types according to the degree of protrusion of the canal from the maxillary roof into the sinus. The prevalence of the IOC types were identified as Type 1, 55.2\%; Type 2, 36\%; Type 3, 8.8\%. The most common type observed in our study group was Type 1 (55.2\%). Haghnegahdar et al. []], Yenigun et al. []], and Ference et al. [1] classified the configuration of the IOC into three types. The most common IOC types were reported as Type $2(50.3 \%)$ by Haghnegahdar et al. [4] , Type $2(51.2 \%)$ by Yenigun et al. [] 
and Type $1(60.5 \%)$ by Ference et al. [1]. Acar et al. [18] considered an additional type (lateroantral type) named IOC Type 4 and they indicated that the most common type was Type $1(55.3 \%)$. The variability in the prevalence rates of IOC protrusion and IOC types may be attributed to racial differences in the observed populations, the differences in patient age groups, and resolution of the assessed images.

Haller's cells or infraorbital ethmoid cells are extensions of the anterior ethmoid sinus into the floor of the orbit and superior aspect of the maxillary sinus. Although Haller's cells are anatomical variations in the development of the nose and paranasal sinuses, they have been associated with various disease processes and symptoms, including sinusitis, headaches, and mucoceles [19]. In the present study, the prevalence of Haller cells were found to be significantly higher in Types 2 and 3 than in Type 1. On the other hand, there was no significant difference in the prevalence of Haller cells when comparing between Types 2 and 3. Moreover, the prevalence of Type 3 increased from $8.2 \%$ in cases without an ipsilateral Haller cell to $14 \%$ when a Haller cell was present, but the difference was not significant. Haghnegahdar et al. [18] reported that the prevalence of Haller cells was significantly higher in Type 2 and 3 than Type 1 . They also reported that the prevalence of Type 3 significantly increased from $14.8 \%$ in cases without an ipsilateral Haller cell to $29.1 \%$ when a Haller cell was present. Ference et al. [1] found that protrusion of the IOC into the maxillary sinus increased from $7.8 \%$ in cases without an ipsilateral infraorbital ethmoid cell to $27.7 \%$ when a cell was present. In other studies, Yenigun et al. [ㅁ] and Acar et al. [18] found no statistically significant correlation between specific IOC types and the presence of the Haller cell. The different findings in the relationships between the Haller cell and IOC types in the studies can be explained by the difference in the frequency of anatomical variations in different populations.

Certain anatomic variations are considered as predisposing factors for the development of sinonasal disease [20]. In our study, no significant difference was found in the prevalence of IOC protrusion between cases with mucosal thickening and cases without mucosal thickening. Moreover, no statistically significant correlation was found between specific IOC types and the presence of mucosal thickening. Ozturk et al. [21] considered the presence of diffuse mucosal thickening with $\geq 5 \mathrm{~mm}$ as sinonasal inflammatory mucosal disease in the frontal, maxillary, and sphenoid sinuses. They found no significant relationship between IOC protrusion and sinonasal inflammatory mucosal disease, consistent with our study.
In our study, four different measurements were performed for Type 3 IOC. The first measurement which included the length of the bony septum from the canal to the sinus wall (D1), was found to be 3.75 (1.76) $\mathrm{mm}$ (range 1.3 to $10.1 \mathrm{~mm}$ ). In the previous studies, the mean septum length was reported as 4.9 $\mathrm{mm}$ (range 0.9 to $8.9 \mathrm{~mm}$ ) by Gautam et al. [17] and $4 \mathrm{~mm}$ (range 1 to $11 \mathrm{~mm}$ ) by Lantos et al. [2]. The second measurement which was the distance at which protrusion begins posterior to the inferior orbital rim (D2), was found to be $9.51(2.03) \mathrm{mm}$ (range 5.9 to $14.8 \mathrm{~mm}$ ) in our study. However, this distance was found to be $11 \mathrm{~mm}$ (range 5 to $24 \mathrm{~mm}$ ) by Lantos et al. [2]. The third measurement, the vertical distance from the canal to the sinus roof (D3) was found to be $6.76(1.78) \mathrm{mm}$ (range 3.3 to $10.7 \mathrm{~mm}$ ) in the present study. This distance was reported to be 8.58 (2.85) $\mathrm{mm}$ by Ference et al. [1] and 11.61 (2.55) $\mathrm{mm}$ by Haghnegahdar et al. [4]. Lastly, the fourth measurement being the vertical distance from the canal to the sinus floor (D4), was found to be 25.44 (4.69) $\mathrm{mm}$ (range 14.2 to $36.4 \mathrm{~mm}$ ) in the present study. To the best of our knowledge, no previous studies have investigated the distance from the canal to the sinus floor. Based on this result, we suggest that the risk of iatrogenic injury to the descending canals is very low during routine dentoalveolar procedures such as tooth extraction, implant placement, etc. in view of the fact that the canal is not close to the sinus floor. However, the protruded ION is at risk for iatrogenic injury during surgical procedures involving the maxillary sinus such as Caldwell-Luc surgery, maxillary resections, tumour removal from the maxillary sinus, and endoscopic sinus surgery.

In this study, the measurements (D1, D2, D3, and D4) were compared between genders. There was no significant difference in the mean D1, D2, and D3 between males and females. However, the mean vertical distance from the canal to the sinus floor (D4) was significantly higher in males than in females. The difference in this distance between genders can probably be attributed to the fact that males are generally physically larger than females in most dimensions.

\section{CONCLUSIONS}

Awareness of the potential anatomical changes in infraorbital canals morphology is essential for a successful surgical procedure performed in this area. The protrusion of infraorbital canals into the maxillary sinus is a common variation that must be considered in the surgical procedures to prevent accidental injury. 
Our findings suggest that the risk of iatrogenic injury to the descending canals is very low during routine dentoalveolar procedures because the protruded canal is not close to the sinus floor. However, the protruded nerve is at risk for iatrogenic injury during extended surgical procedures involving the maxillary sinus. Preoperative radiological assessment of the infraorbital canals can prevent iatrogenic injuries and surgical complications.

\section{ACKNOWLEDGMENTS AND DISCLOSURE STATEMENTS}

The authors report no conflicts of interest related to this study. Also, this research did not receive any specific grant from funding agencies in the public, commercial, or not-for-profit sectors.

\section{REFERENCES}

1. Ference EH, Smith SS, Conley D, Chandra RK. Surgical anatomy and variations of the infraorbital nerve. Laryngoscope. 2015 Jun;125(6):1296-300. [Medline: 25992806] [doi: 10.1002/lary.25089]

2. Lantos JE, Pearlman AN, Gupta A, Chazen JL, Zimmerman RD, Shatzkes DR, Phillips CD. Protrusion of the Infraorbital Nerve into the Maxillary Sinus on CT: Prevalence, Proposed Grading Method, and Suggested Clinical Implications. AJNR Am J Neuroradiol. 2016 Feb;37(2):349-53. [Medline: 26564432] [doi: 10.3174/ajnr.A4588]

3. Leo JT, Cassell MD, Bergman RA. Variation in human infraorbital nerve, canal and foramen. Ann Anat. 1995 Jan;177(1): 93-5. [Medline: 7872502] [doi: 10.1016/S0940-9602(11)80139-1]

4. Haghnegahdar A, Khojastepour L, Naderi A. Evaluation of Infraorbital Canal in Cone Beam Computed Tomography of Maxillary Sinus. J Dent (Shiraz). 2018 Mar;19(1):41-47. [Medline: 29492415] [PMC free article: 5817342]

5. Elnil H, Al-Tubaikh JA, El Beltagi AH. Into the septum I go, a case of bilateral ectopic infraorbital nerves: a not-to-miss preoperative sinonasal CT variant. Neuroradiol J. 2014 Apr;27(2):146-9. [Medline: 24750699] [PMC free article: 4202867] [doi: 10.15274/NRJ-2014-10033]

6. Yenigun A, Gun C, Uysal II, Nayman A. Radiological classification of the infraorbital canal and correlation with variants of neighboring structures. Eur Arch Otorhinolaryngol. 2016 Jan;273(1):139-44. [Medline: 25673024] [doi: 10.1007/s00405-015-3550-8]

7. Al Abduwani J, ZilinSkiene L, Colley S, Ahmed S. Cone beam CT paranasal sinuses versus standard multidetector and low dose multidetector CT studies. Am J Otolaryngol. 2016 Jan-Feb;37(1):59-64. [Medline: 26700263] [doi: 10.1016/j.amjoto.2015.08.002]

8. Olutayo J, Agbaje JO, Jacobs R, Verhaeghe V, Velde FV, Vinckier F. Bisphosphonate-Related Osteonecrosis of the Jaw Bone: Radiological Pattern and the Potential Role of CBCT in Early Diagnosis. J Oral Maxillofac Res. 2010 Jul 1; 1(2):e3. [Medline: 24421968] [PMC free article: 3886047] [doi: 10.5037/jomr.2010.1203]

9. Rak KM, Newell JD 2nd, Yakes WF, Damiano MA, Luethke JM. Paranasal sinuses on MR images of the brain: significance of mucosal thickening. AJR Am J Roentgenol. 1991 Feb;156(2):381-4. [Medline: 1898819] [doi: 10.2214/ajr.156.2.1898819]

10. Günbey E, Günbey HP, Uygun S, Karabulut H, Cingi C. Is preoperative paranasal sinus computed tomography necessary for every patient undergoing septoplasty? Int Forum Allergy Rhinol. 2015 Sep;5(9):839-45. [Medline: 25963400] [doi: $10.1002 /$ alr.21545]

11. Mostafa BE, Khafagi A. Combined HRCT and MRI in the detection of CSF rhinorrhea. Skull Base. 2004 Aug;14(3): 157-62; discussion 162. [Medline: 16145599] [PMC free article: 1151686] [doi: 10.1055/s-2004-832259]

12. Langner S. Optimized imaging of the midface and orbits. GMS Curr Top Otorhinolaryngol Head Neck Surg. 2015 Dec 22;14:Doc05. [Medline: 26770279] [PMC free article: 4702054] [doi: 10.3205/cto000120]

13. Ferreira LM, Nejaim Y, Freitas DQ, Tabchoury CPM. The fundaments of cbct and its use for evaluation of paranasal sinuses: review of literature. Braz J Oral Sci. 2018 Jun;17:e18038. [doi: 10.20396/bjos.v17i0.8652646]

14. da Costa ED, Verner FS, Peyneau PD, de Freitas DQ, de Almeida SM. Diagnosis of ethmoid sinolith by cone-beam computed tomography: case report and literature review. Oral Radiol. 2019 Jan;35(1):68-72. [Medline: 30484175] [doi: $10.1007 / \mathrm{s} 11282-017-0310-\mathrm{z}]$

15. Bahşi I, Orhan M, Kervancıoğlu P, Yalçın ED. Morphometric evaluation and surgical implications of the infraorbital groove, canal and foramen on cone-beam computed tomography and a review of literature. Folia Morphol (Warsz). 2019;78(2):331-343. [Medline: 30178457] [doi: 10.5603/FM.a2018.0084]

16. Chandra RK, Kennedy DW. Surgical implications of an unusual anomaly of the infraorbital nerve. Ear Nose Throat J. 2004 Nov;83(11):766-7. [Medline: 15628633] [doi: 10.1177/014556130408301113]

17. Gautam R, Adhikari D, Dhital M, Thakur S, Adhikari B. The Prevalence of Protrusion of Infraorbital Nerve into Maxillary Sinus identified on CT Scan of the Paranasal Sinuses at a Tertiary Hospital in Nepal. NJR. 2018 Jan-Jun;8(1):7-12. [doi: 10.3126/njr.v8i1.20440] 
18. Açar G, Özen KE, Güler İ, Büyükmumcu M. Computed tomography evaluation of the morphometry and variations of the infraorbital canal relating to endoscopic surgery. Braz J Otorhinolaryngol. 2018 Nov-Dec;84(6):713-721. [Medline: 28943288] [doi: 10.1016/j.bjorl.2017.08.009]

19. Pekiner FN, Borahan MO, Dumlu A, Özbayrak S. Infraorbital ethmoid (Haller) cells: a cone-beam computed tomographic study. Oral Radiol. 2014 Sep;30(3):219-25. [doi: 10.1007/s11282-014-0167-3]

20. Wani AA, Kanotra S, Lateef M, Ahmad R, Qazi SM, Ahmad S. CT scan evaluation of the anatomical variations of the ostiomeatal complex. Indian J Otolaryngol Head Neck Surg. 2009 Sep;61(3):163-8. [Medline: 23120628] [PMC free article: 3449989] [doi: 10.1007/s12070-009-0059-8]

21. Kurtuluş Öztürk EK, Öztürk S, Turan Ş, Acu B. Sinonasal anatomic variations and relationship with sinonasal inflammatory mucosal disease: a computed tomography study. J Contemp Med. 2020 Sep;10(3):348-53. [doi: 10.16899/jcm.746980]

\section{To cite this article:}

Kalabalık F, Aktaş T, Akan E, Aytuğar E.

Radiographic Evaluation of Infraorbital Canal Protrusion into Maxillary Sinus Using Cone-Beam Computed Tomography J Oral Maxillofac Res 2020;11(4):e5

URL: http://www.ejomr.org/JOMR/archives/2020/4/e5/v11n4e5.pdf

doi: $\underline{10.5037 / j o m r .2020 .11405}$

Copyright (C) Kalabalık F, Aktaş T, Akan E, Aytuğar E. Published in the JOURNAL OF ORAL \& MAXILLOFACIAL RESEARCH (http://www.ejomr.org), 31 Dcember 2020.

This is an open-access article, first published in the JOURNAL OF ORAL \& MAXILLOFACIAL RESEARCH, distributed under the terms of the Creative Commons Attribution-Noncommercial-No Derivative Works 3.0 Unported License, which permits unrestricted non-commercial use, distribution, and reproduction in any medium, provided the original work and is properly cited. The copyright, license information and link to the original publication on (http://www.ejomr.org) must be included. 